NBER WORKING PAPER SERIES

FADING STARS

Germán Gutiérrez

Thomas Philippon

Working Paper 25529

http://www.nber.org/papers/w25529

\author{
NATIONAL BUREAU OF ECONOMIC RESEARCH \\ 1050 Massachusetts Avenue \\ Cambridge, MA 02138 \\ February 2019
}

We are grateful to the Smith Richardson Foundation for a research grant, and to seminar participants at the NBER, University of Chicago, New York University, and the 2019 AEA meetings for stimulating discussions, to David Autor, Olivier Blanchard, Xavier Gabaix and John Van Reenen for their comments, and to Steve Davis for his comments, discussion, and suggestions. The views expressed herein are those of the authors and do not necessarily reflect the views of the National Bureau of Economic Research.

NBER working papers are circulated for discussion and comment purposes. They have not been peer-reviewed or been subject to the review by the NBER Board of Directors that accompanies official NBER publications.

(C) 2019 by Germán Gutiérrez and Thomas Philippon. All rights reserved. Short sections of text, not to exceed two paragraphs, may be quoted without explicit permission provided that full credit, including $\odot$ notice, is given to the source. 
Fading Stars

Germán Gutiérrez and Thomas Philippon

NBER Working Paper No. 25529

February 2019

JEL No. D2,E22,E24,F6,G3,L1,O3,O4

\section{ABSTRACT}

We study the evolution of super star firms in the U.S. economy over the past 60 years. Contrary to common wisdom, super stars firms have not become larger, have not become more productive, and the contribution of star firms to aggregate U.S. productivity growth has fallen by more than one third since 2000 .

Germán Gutiérrez

NYU Stern School of Business

44 West 4th Street

KMC 9-190

New York, NY 10012

ggutierr@stern.nyu.edu

Thomas Philippon

New York University

Stern School of Business

44 West 4th Street, Suite 9-190

New York, NY 10012-1126

and NBER

tphilipp@stern.nyu.edu 


\title{
Fading Stars*
}

\author{
Germán Gutiérrez ${ }^{\dagger}$ and Thomas Philippon ${ }^{\ddagger}$
}

January 2019

\begin{abstract}
We study the evolution of super star firms in the U.S. economy over the past 60 years. Contrary to common wisdom, super stars firms have not become larger, have not become more productive, and the contribution of star firms to aggregate U.S. productivity growth has fallen by more than one third since
\end{abstract} 2000.

A large and growing literature emphasizes the role of large firms in the economy. Large firms dominate exports, foreign direct investment, and research and development. The top firm accounts for more than $14 \%$ of exports in most countries (Freund and Denisse Pierola, 2015). Companies with more than 5,000 employees accounted for two thirds of the $\$ 375$ billion that U.S. Businesses spent on R\&D in 2016 (Wolfe, 2018). Gabaix (2011) argues that idiosyncratic shocks to large firms can explain some of the fluctuations in GDP.

Moreover, we know from previous research that, over the past 20 years, US firms' profit margins have increased and U.S. industries have become more concentrated, although there is disagreement about how to interpret this fact (Furman, 2015; Grullon et al., 2016; Gutiérrez and Philippon, 2017b). ${ }^{1}$ Two leading explanations have been proposed. One is that top firms have become increasingly more efficient than other firms in their respective industries. This might explain why their market shares and their profits have grown. According to this view, concentration is good news and high profits reflect high efficiency (Autor et al., 2017). The other explanation is that domestic competition has decreased and that leaders have become more

${ }^{*}$ We are grateful to the Smith Richardson Foundation for a research grant, and to seminar participants at the NBER, University of Chicago, New York University, and the 2019 AEA meetings for stimulating discussions, to David Autor, Olivier Blanchard, Xavier Gabaix and John Van Reenen for their comments, and to Steve Davis for his comments, discussion, and suggestions.

${ }^{\dagger}$ New York University

${ }^{\ddagger}$ New York University, CEPR and NBER

${ }^{1}$ On the empirical side, a growing literature that documents the rise in concentration, profits, and markups in the U.S. Grullon et al. (2016) show that concentration and profit rates have increased across most U.S. industries. Furman (2015) and CEA (2016) argue that the rise in concentration suggests "economic rents and barriers to competition." Barkai (2017) also find an increase in excess profits and De Loecker and Warzynski (2012) argue that markups have increased. Gutiérrez and Philippon (2018b) study the role of governance and its interaction with concentration. Not all concentration is bad, of course. Alexander and Eberly (2016) and Crouzet and Eberly (2018) argue that the rise in intangible investment can account, in some industries (e.g. retail trade) for the rise in concentration and the decrease in measured investment. 
entrenched. Their market shares are not threatened and they can charge high prices. According to this view, concentration is bad news (Gutiérrez and Philippon, 2017a). The two explanations are not mutually exclusive, in the sense that leaders can become more efficient and more entrenched at the same time. In particular, leaders might be particularly efficient at using intangible assets (Crouzet and Eberly, 2018). This can explain their growth, but also create rising barriers to entry. But, fundamentally, the two explanations have opposite implications for efficiency, growth, welfare and policy.

The optimistic view seems to take as given the idea that superstar firms are becoming larger, more productive, and are pulling away from the rest of the economy. The actual evidence, however, is weaker and more indirect than commonly acknowledged. Andrews et al. (2015) document an increased dispersion in output per worker between global "frontier" firms and "laggard" firms. When applying this idea to the US, most commentators jump to the conclusion that Google and Facebook (for instance) have outstanding productivity growth, and that the problem lies with the rest of the economy. In the global data of Andrews et al. (2015), however, the average frontier firm in Manufacturing has about $\$ 50$ million in revenues and 74 employees (see their Table 1b). The revenues of frontier firms in Services is about $\$ 80$ million. These firms are not what most people have in mind when they talk about the "stars" of the new economy. They are two order of magnitude smaller. Autor et al. (2017) have popularized the term "superstar firms." They show that the fall in the labor share is explained by a composition shift towards establishments with low labor shares. This, by itself, does not mean that superstar firms are becoming either larger or more productive.

The point of our paper is simple: we actually look directly at super star firms over the past 60 years in the US. What we find contradicts the common wisdom. We show that: (i) super-star firms have not become larger; super-star firms have not become more productive; the contribution of super-star firms to overall productivity growth has decreased by about $40 \%$ over the past 20 years.

\section{Data}

We use firm-level data from the CRSP-Compustat merged database, which covers all public and some private firms in the U.S. Economy. We complement these data with three sources: first, we obtain Employment, as well as Gross Output quantities and prices from the BEA GDP by Industry accounts. These data cover 20 sectors since 1948 and 62 industries since 1977. We use these data to estimate industry-level labor productivity and to deflate Compustat sales and compute firm-level labor productivity.

Second, we obtain domestic and foreign sales at the industry-level from the BEA's Data on the Activities of U.S. Multinational Enterprises. Industry segments roughly follow the 62 industries in the GDP by Industry accounts. We estimate the share of foreign sales in a given industry as the ratio of sales by 'Majority-owned Foreign Affiliates of U.S. Multinational Enterprises' (MOFA) to total sales, defined as the sum of U.S. Parent sales and MOFA sales.

Last, we obtain payroll, employment and sales for the top 4 firms in each industry and the industry as a whole from the U.S. Economic Census concentration accounts. We map these industries to BEA segments as closely as possible and use the data to compute the labor-quality adjustment and perform robustness tests on the contribution of stars. See Appendix A for additional details on data sources and definitions. 


\section{Footprint of the Stars}

We start with some simple descriptive statistics. Figure 1 shows the foot print of stars in the U.S. economy. We define star firms in two ways for our main analysis. We present a complete list of alternative definitions and results in the Appendix (using top 100 firms, using revenues instead of market value, etc.).

- Top 20 firms by market value of equity in any given year (Top 20).

- These are economy-wide stars. The industry composition varies significantly over time. The stars of the 1950s were often manufacturing firms (GM, GE). IBM appears in the 1960s. Microsoft and Walmart appear in the 1990s. And of course Google, Amazon and Facebook in recent years.

- Top 4 firms by market value of equity within each 3-digit industry (Top 4 by Industry).

- These are industry stars. Since we have 62 industries, there are 248 such industry stars each year. By construction, the industry composition by number of firms is constant. These industry stars include most of the economy-wide stars unless a national star happens to be the fifth in an industry. This actually happens early in the sample, especially when including Oil.

The top panel of 1 shows the shares of stars in civilian employment. The Top 20 employed about $4 \%$ of US workers in the 1960s. It decreased to about $2 \%$ in the late 1990s and grew back afterwards, essentially because of the arrival of Walmart among the stars. The Top 4 by Industry is more stable around 8\%. Clearly, as far as employment is concerned, the stars are not becoming larger.

The bottom panel of 1 shows the shares of stars in sales over GDP. The sales over GDP ratio is of course critically important because of Hulten (1978), as we discussed in the next section. For each group of stars, we report the consolidated sales and the domestic sales. To compute domestic sales, we subtract the export shares of top firms by industries using detailed data from the BEA's Data on the activities of U.S. Multinational Enterprises. ${ }^{2}$ The figure shows that, contrary to common wisdom, the stars have not become larger in terms of sales.

Fact 1. The economic footprint of the stars has not increased.

The stable employment footprint is a known fact (see Autor et al. 2017 for instance). The fact that revenues are stable as a share of GDP is new and surprising. Figure 1 in Gabaix (2011) reports that sales of the top 50 firms are $24 \%$ of GDP, while the sales of the top 100 firms are $29 \%$ of GDP. These numbers are for consolidated revenues and we estimate that about $1 / 3$ are exports. Moreover the share exported has grown over time. Consolidated sales over domestic GDP therefore do not provide a reliable picture of the evolution of large firms. One could either scale global sales by global GDP, or domestic sales by domestic GDP, which is what we do in this paper. Once we perform this export adjustment, we overturn the common wisdom that stars have become larger relative to the economy.

\footnotetext{
${ }^{2}$ The data is available at link
} 
Figure 1: Footprint of the Stars
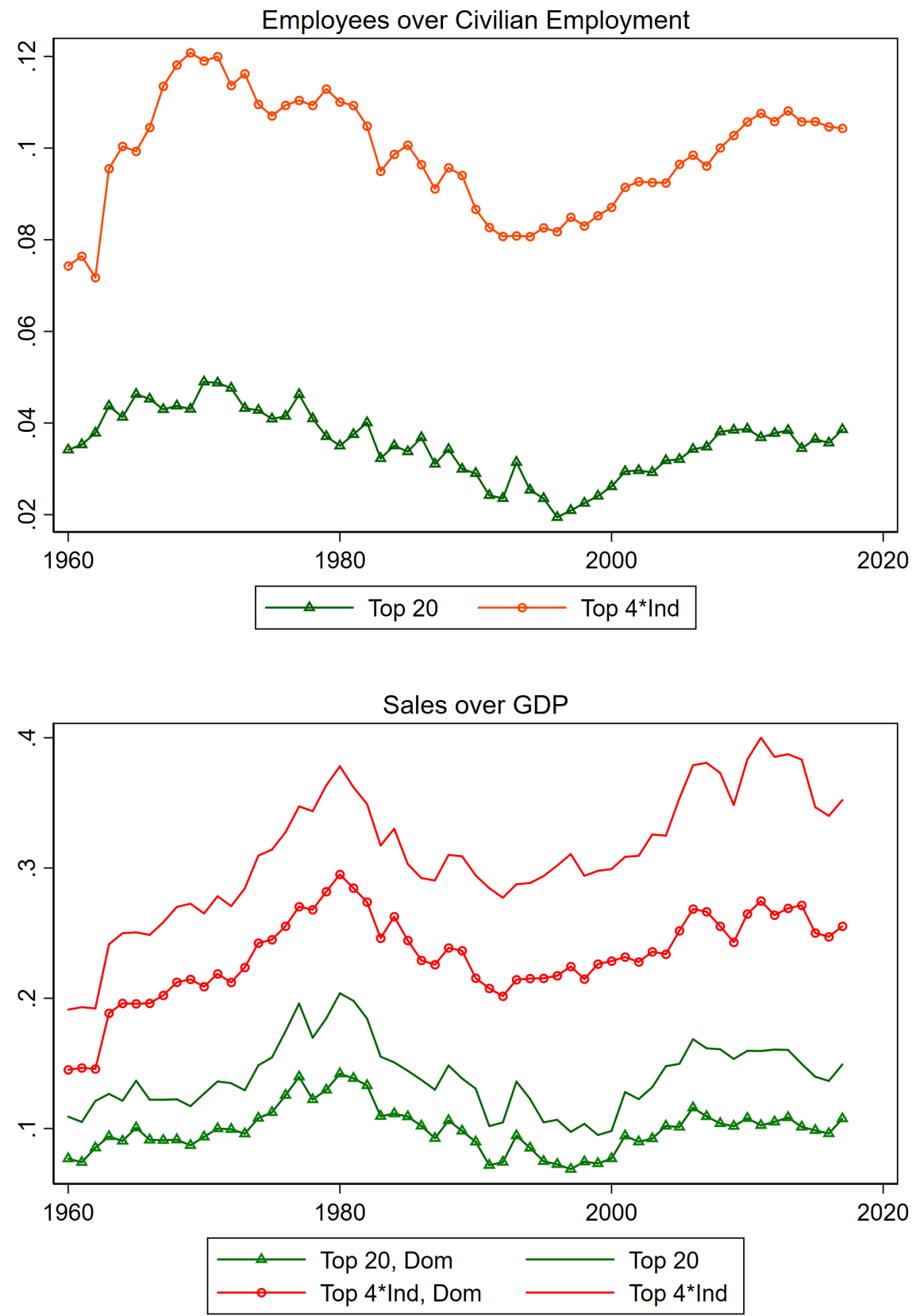

Note: See text for definitions. For bottom panel, "Dom" means domestic sales, while "Top 20" means consolidated (global) sales of Top 20 firms by market value. 


\section{Hulten Contribution}

The classic Theorem of Hulten (1978) - recently extended by Baqaee and Farhi (2018) - shows that the contribution of an individual firm to aggregate productivity growth equals its own productivity times its Domar weight. Figure 2 shows that the Hulten contribution of the stars has collapsed since 2000. The Hulten contribution is defined as the Domar weight times the firm level increase in log sales per employee. It is a "within" contribution since it uses the initial Domar weight times future productivity growth: ${ }^{3}$

$$
g_{t}^{h *} \equiv \sum_{i \in S_{t}} \omega_{i, t} g_{i, t}^{z}
$$

where $S_{t}$ denotes the set of star firms, as defined earlier. The Domar weight $\omega_{i, t}$ of firm $i$ at time $t$ is based on domestic sales: $\omega_{i, t} \equiv \frac{\left(1-e_{i, t}\right) \text { sales }_{i, t}}{G D P_{t}}$, and $e_{i, t}$ is the share of sales that are exported. As a robustness check we also use total costs instead of sales. Productivity growth is averaged over 3 years:

$$
g_{i, t}^{z} \equiv \Delta \log z_{i, t}+\Delta \log z_{i, t+1}+\Delta \log z_{i, t+2}=\log z_{i, t+2}-\log z_{i, t-1},
$$

where $z_{i, t} \equiv \frac{\text { sales }_{i, t}}{q_{i, t} n_{i, t}}$ where $n$ is the number of employees and $q$ is a labor quality adjustment based on relative wages. We obtain the average wage of employees in the top 4 firms in each industry from the census and we define $q$ as the ratio to the average wage in the industry. This adjustment makes only a small difference to the Hulten component, but it is important for the reallocation measure, and we introduce it here to be consistent.

Figure 2 shows that super stars have played a key role in making the economy grow. Historically, they have contributed half a percent to total labor productivity growth (based on industry stars, bottom panel). In recent years, however, their "within" contribution to over productivity growth has been essentially zero.

Fact 2. The Hulten contribution of the stars has dropped from about 50 basis point per year to zero since 2000 .

The result is the same if we use sales or total cost (appropriate under market power) as Domar weights. One possible explanation is that ideas are becoming harder to find as argued by Bloom et al. (2018).

\section{Reallocation}

The Hulten contribution assumes that revenue factor productivities are equalized across firms. If the stars have higher revenue productivity than other firms, then they can contribute to productivity growth simply by drawing in more resources. This is what the literature calls the reallocation effect. The Hulten contribution would fail to pick that up. We define the reallocation contribution of the stars as

$$
g_{t}^{r *} \equiv \sum_{i \in S_{t}}\left(z_{i, t}-\bar{z}_{I, t}\right) g_{i, t}^{n}
$$

\footnotetext{
${ }^{3}$ Our results hold with or without oil companies, but oil shocks in the 1970 s create a lot of noise in reallocation measures so we choose to exclude oil and gas in our benchmark figures.
} 
Figure 2: Hulten Contributions of the Stars
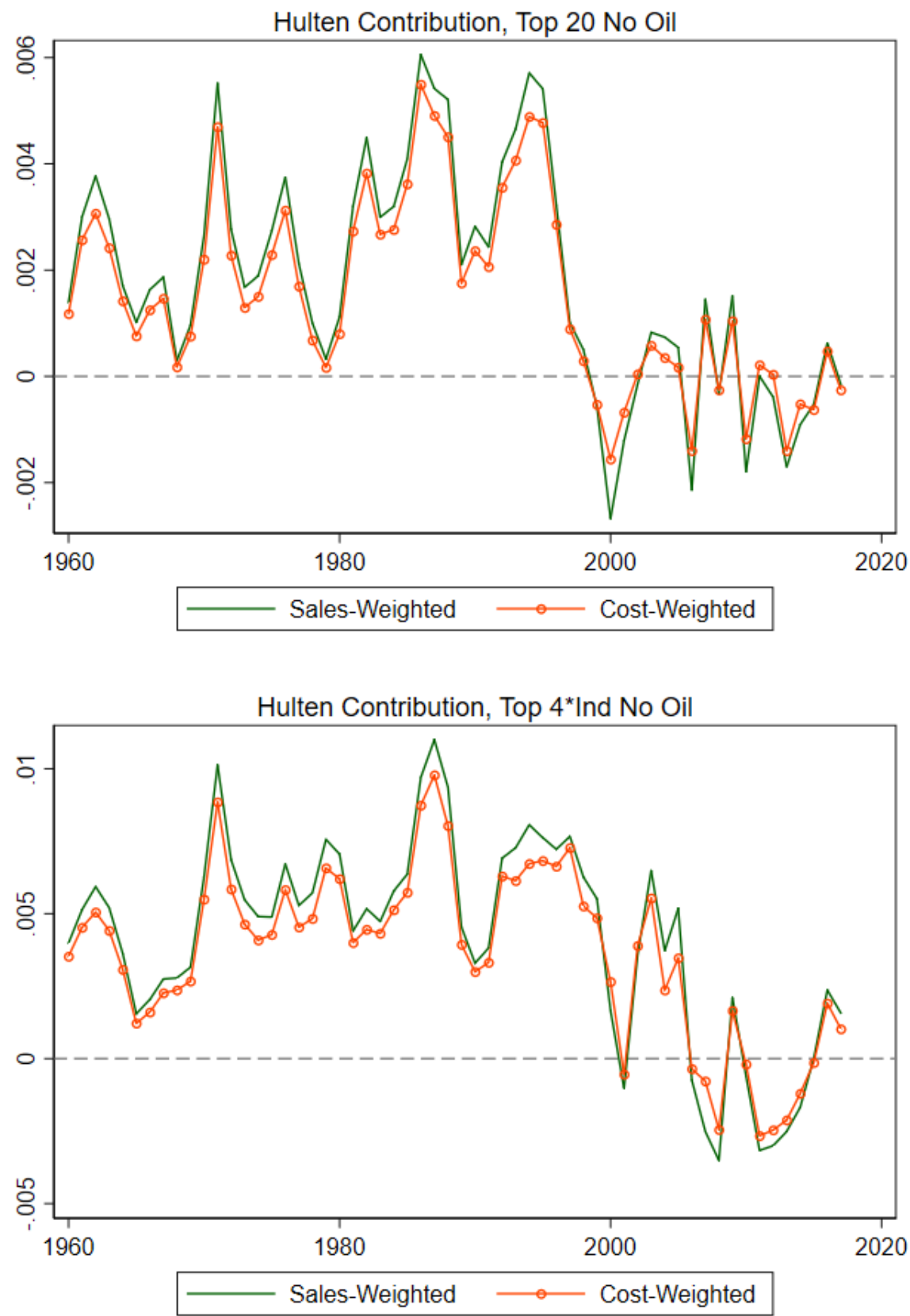

Note: Green line uses sales/GDP as Domar weight. Red line uses cost/GDP as Domar weight. 
Figure 3: Different Benchmarks for Measuring Reallocation

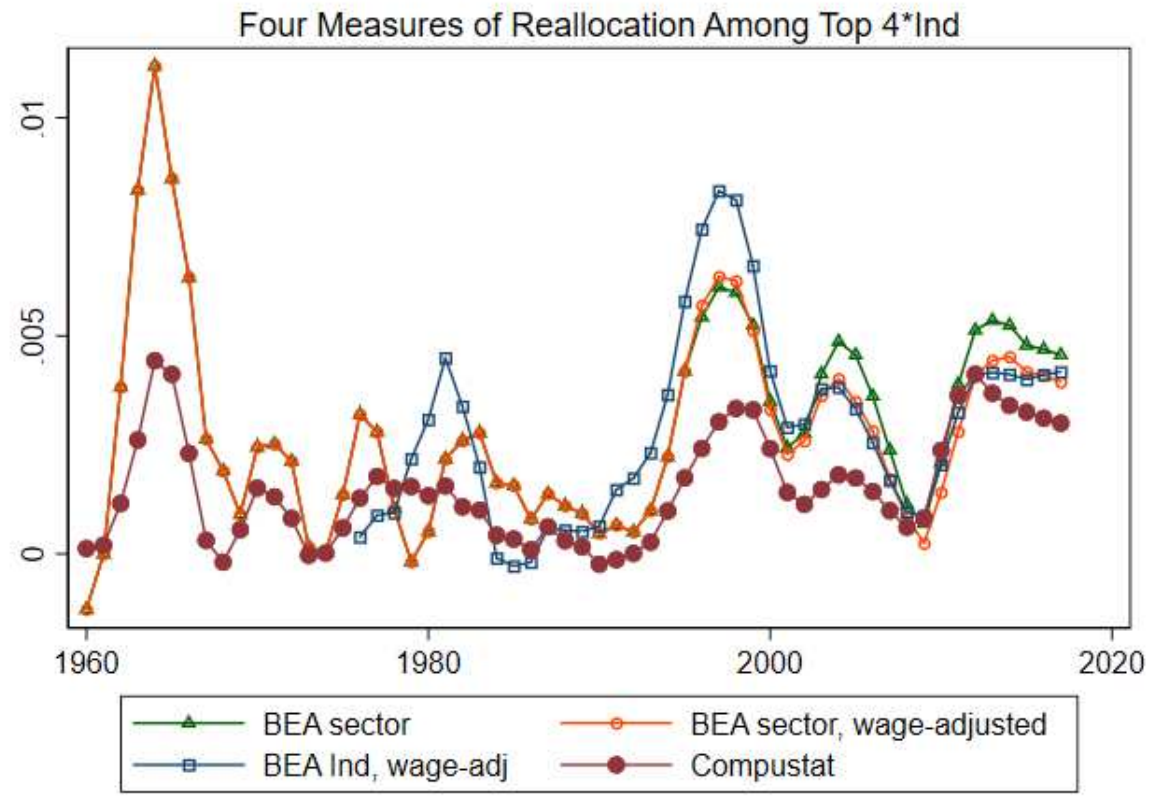

Note: 4 measures of reallocation productivity, using 4 benchmarks: average sector productivity from BEA; sector BEA adjusted for labor quality; industry BEA and Compustat industry average. BEA industry productivity available only after 1977.

Figure 4: Reallocation Contribution of the Stars

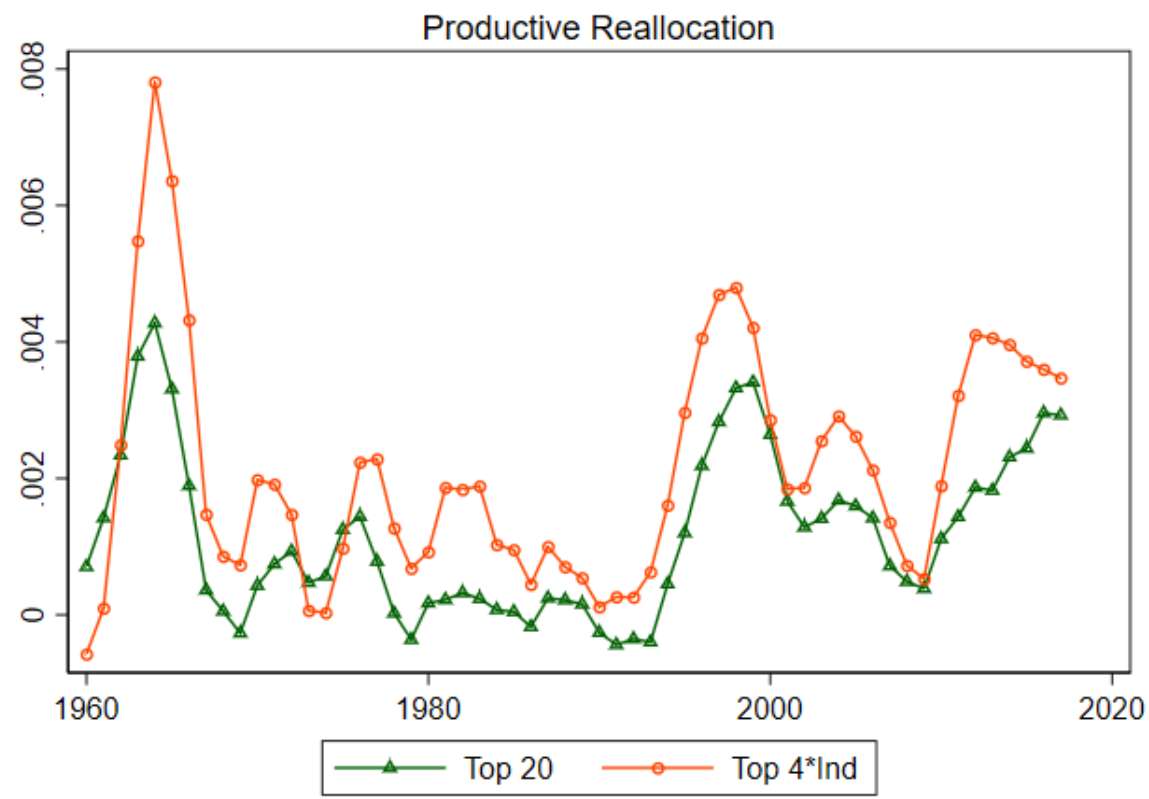

Note: Reallocation productivity defined as average of Compustat and Labor Quality Adjusted measures. 
where $\bar{z}_{I, t}$ is labor productivity in industry $I$ at time $t$. The growth of employment is averaged over 3 years

$$
g_{i, t}^{n} \equiv \Delta \log n_{i, t}+\Delta \log n_{i, t+1}+\Delta \log n_{i, t+2}=\log n_{i, t+2}-\log n_{i, t-1}
$$

Recall that $z_{i, t} \equiv \frac{\text { sales }_{i, t}}{q_{i, t} n_{i, t}}$ is quality adjusted. This adjustment is small before 1995 but reaches $30 \%$ in the 2000s, as shown in the Appendix. Figure 3 shows the impact of various possible adjustments. The red-circle line uses quality adjusted labor. Without the quality adjustment - i.e., assuming that stars hire the 'average' worker in their industry - we get the green triangle line. If instead we assume that stars poach the extra worker from other large firms, we get the blue square line. It seems clear that the green line is misleading, while both the red and the blue are sensible choices. For simplicity, we just use the average of the two. ${ }^{4}$

Figure 4 shows the reallocation contribution of the stars. The reallocation contribution has increased since the mid 1990s, bringing about 20 basis point of productivity growth on average.

Fact 3. The reallocation contribution of the stars has increased modestly.

The overall increase in the reallocation contribution comes in part from the growing importance of nonmanufacturing sectors. The average contribution of reallocation is larger outside manufacturing than inside manufacturing. This is consistent with the evidence in Mansury and Love (2008) who argue that innovation in business services has a positive effect on growth (size) but not on measured productivity. In other words, in the service sector, the "innovation" might be to reach and convince new clients, as opposed to reducing the unit cost of existing services. It is also interesting to see that the increased in the reallocation contribution coincides with the decrease in the Hulten contribution.

\section{Total Contribution of Stars}

Figure 5 shows the total contribution, Hulten plus reallocation, of the stars to US labor productivity growth. The blue and green lines are based on Compustat. From 1960 to 2000, it was about 72 basis point per year on average for the industry stars (33 bps for the Top 20). After 2000 the contributions are only 43 basis points (19 bps for the Top 20).

One might worry that large private firms are missing from Compustat. The gray line therefore uses the Census' Concentration series for non-manufacturing industries, which report sales and employment for the Top 4 firms by industry. The Census data exhibits similar patterns as the Top4*Ind Compustat series. The level of contributions in the Census is lower because only a subset of industries are included. As shown in the Appendix, Compustat and Census-based series are very close to each once restricting the Compustat sample to the industries covered by the Census.

Fact 4. The contribution of star firms to US labor productivity has decreased by about $40 \%$ since 2000, and it has shifted from within firm productivity growth to reallocation driven growth.

\footnotetext{
${ }^{4}$ One issue with this measure of growth through reallocation is that it does not distinguish between organic growth and external growth. In the case of mergers and acquisitions, it might not be valid to apply the initial productivity of the acquirer to the employees of the target, at least not in the short run. This can affect the decomposition of growth into the 'within' Hulten part and the 'between' reallocation part. We leave this question for future research.
} 
Figure 5: Total Contributions of the Stars

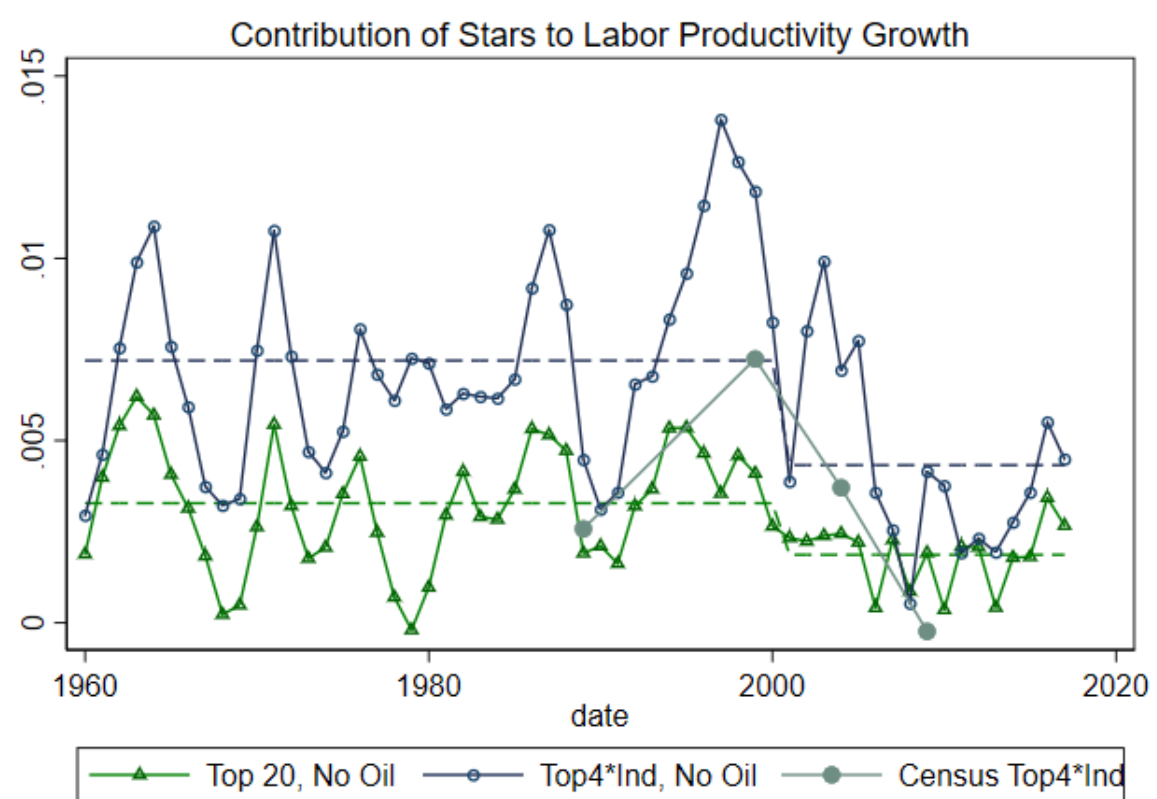

Note: the figure plots the contributions of star firms to US labor productivity growth. The dashed lines show the averages for 1960-2000, and 2001-2016. Top 20 averages: 33 bps down to 19 bps. Top 4 by Industry averages: 72 bps down to 43 bps.

Over the same period, total labor productivity growth has also fallen. Figure 6 shows aggregate labor productivity growth from Fernald (2014), and the contribution of non-stars, defined as the difference between aggregate productivity growth and the industry-star contribution. Non-stars contribute more than stars to overall growth and explain most of the time series variations, such as the sharp drop around 1980 or the revival of the late 1990s. They account for most of the cumulative growth since 2000. However, their contribution has collapsed after the great recession, while that of the stars has picked up a little bit since 2013.

\section{Conclusion}

Our results challenge the common wisdom about the stars of the new economy and shed light on the debate between Brynjolfsson and McAfee (2014), who view digital technologies as "the most general purpose of all", and Gordon (2016) who is skeptical about the impact of recent innovations. Our results are perhaps less surprising for students of history. There is a natural bias to think that today is different - to paraphrase Reinhart and Rogoff (2009) - and this to think that our current stars are exceptional. But there has always been star firms in the U.S. economy, and they have always been large and productive. In our data, we find that today's stars are no match (so far) for yesterday's stars.

The next question, of course, is why star firms are not contributing as much as they used to. We do not have a definite answer but it is clear that something changed around 2000. Perhaps ideas are becoming harder to find as Bloom et al. (2018) argue. Or perhaps declining competition and rising barriers to entry 
Figure 6: Total Contributions of Stars and Non Stars

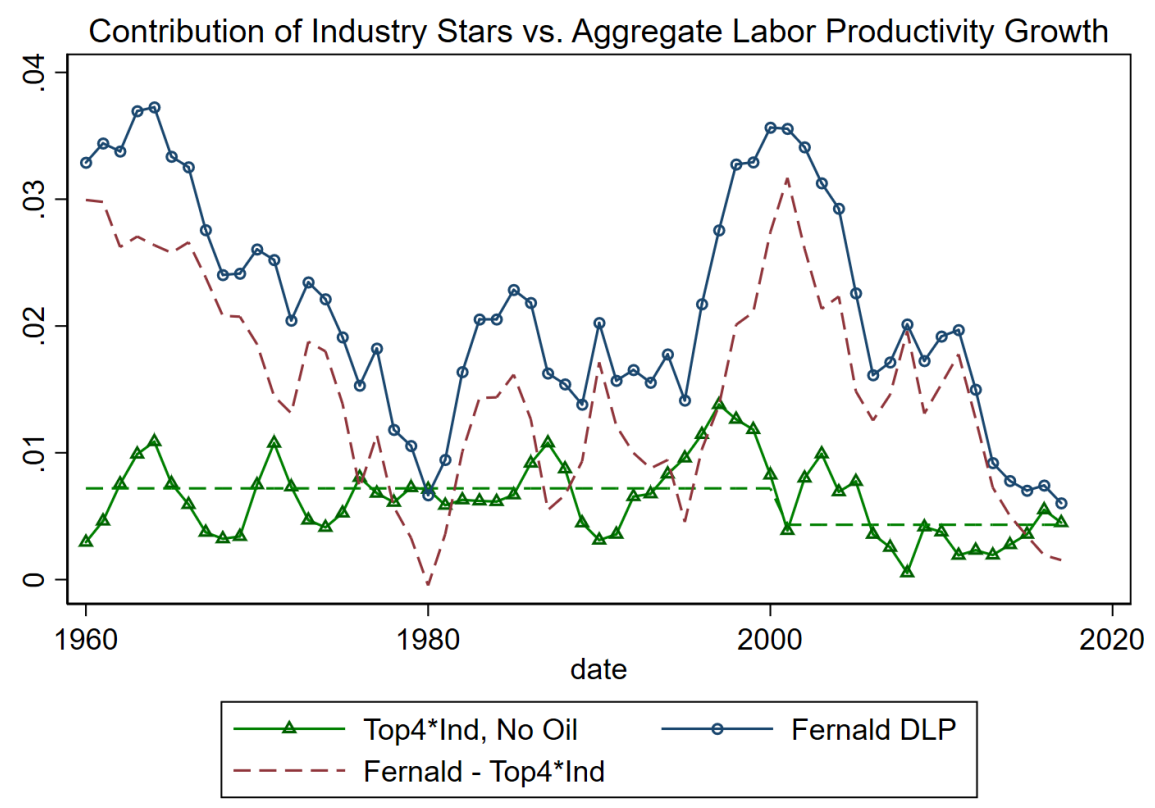

Note: the figure plots the contributions of star firms to US labor productivity growth, including 5Y MA growth in U.S. labor productivity as measured by Fernald (2014).

have allowed incumbents to cut investment and innovation. Davis (2017) argues that barriers to entry arise from excessively complex regulations. Indeed, in Gutiérrez and Philippon (2018a), we find that the free entry condition starts to break down around 2000. The elasticity of entry with respect to profits and/or Tobin's $Q$ has declined over the past 30 years and is now zero. We find rising barriers to entry from lobbying and regulations that seems to benefit large firms. Facing less competition, their incentives to invest and innovate decrease. The investment rate of large and profitable firms has remained surprisingly low as their payout rate (dividends and stock buybacks) has increased. This is presumably part of the explanation. 


\section{References}

Alexander, L. and J. Eberly (2016). Investment hollowing out. Working Paper.

Andrews, D., C. Criscuolo, and P. N. Gal (2015). Frontier firms, technology diffusion and public policy: Micro evidence from oecd countries. OECD Working Paper.

Autor, D., D. Dorn, L. F. Katz, C. Patterson, and J. V. Reenen (2017). The fall of the labor share and the rise of superstar firms.

Baqaee, D. R. and E. Farhi (2018). The macroeconomic impact of microeconomic shocks: Beyond hulten's theorem.

Barkai, S. (2017). Declining labor and capital shares. University of Chicago.

Bloom, N., C. I. Jones, J. V. Reenen, and M. Webb (2018). Are ideas getting harder to find?

Brynjolfsson, E. and A. McAfee (2014). The Second Machine Age. New York.

CEA (2016, April). Benefits of competition and indicators of market power. Issue Brief.

Crouzet, N. and J. Eberly (2018). Intangibles, investment, and efficiency. AEA Papers and Proceedings.

Davis, S. (2017). Regulatory complexity and policy uncertainty: Headwinds of our own making. Booth Working Paper.

De Loecker, J. and F. Warzynski (2012, May). Markups and firm-level export status. American Economic Review 102(6), 2437-71.

Dorn, D., J. F. Schmieder, and J. R. Spletzer (2018). Domestic outsourcing in the united states.

Fernald, J. (2014). A quarterly, utilization-adjusted series on total factor productivity. FRB Working paper.

Freund, C. and M. Denisse Pierola (2015). Export superstars. The Review of Economics and Statistics 97, $1023-1032$.

Furman, J. (2015). Business investment in the united states: Facts, explanations, puzzles, and policies.

Gabaix, X. (2011). The granular origins of aggregate fluctuations. Econometrica 79.

Gordon, R. J. (2016). The Rise and Fall of American Growth. Princeton University Press.

Grullon, G., Y. Larkin, and R. Michaely (2016). Are us industries becoming more concentrated?

Gutiérrez, G. and T. Philippon (2017a). Declining competition and investment in the u.s.

Gutiérrez, G. and T. Philippon (2017b). Investment-less growth: An empirical investigation. Brookings Papers on Economic Activity Fall. 
Gutiérrez, G. and T. Philippon (2018a). The failure of free entry.

Gutiérrez, G. and T. Philippon (2018b). Ownership, governance and investment. AEA Papers and Proceedings.

Hulten, C. R. (1978). Growth accounting with intermediate inputs. Review of Economic Studies 45(3), $511-518$.

Mansury, M. A. and J. H. Love (2008). Innovation, productivity and growth in us business services: A firm-level analysis. Technovation 28(1), $52-62$.

Raymond J. Mataloni, J. (1995). A guide to bea statistics on u.s. multinational companies. Survey of Current Business.

Reinhart, C. M. and K. S. Rogoff (2009). This Time Is Different: Eight Centuries of Financial Folly. Princeton University Press.

Wolfe, R. (2018, September). Businesses spent 375 billion on research and development. Infobriefs. 


\section{Appendices}

\section{A Data Appendix}

\section{A.1 Aggregate data}

We use FRED series CE16OV for total civilian employment and GDPA for annual GDP in billion USD.

\section{A.2 Industry-level data}

\section{A.2.1 Gross Output, Prices and Employment}

We obtain Gross Output, Prices and Employment from the BEA GDP By Industry accounts, which roughly follow NAICS-3 industries. These data are used to (i) deflate sales of Compustat firms and (ii) compute sector and industry-level labor productivity, which are used as benchmarks in our reallocation calculations.

Nominal and Real Gross Output as well as Gross Output price indices are based on file 'GDPbyInd_GO_19472017'. Data covers 20 sectors (splitting durable and nondurable manufacturing) and 62 industries. We combine the 'Hospitals' and 'Nursing and residential care facilities' as well as the 'Motor vehicles, bodies and trailers, and parts' and 'Other transportation equipment' because some data are only available at the more aggregated level before 1997. We also drop 'Management of companies and enterprises' because there are no firms that map to this industry in Compustat. Last, we add an 'other' segment which covers firms with NAICS or SIC codes of $99^{*}$ which cannot be mapped to individual industries. ${ }^{5}$

Employment data is based on file GDPbyInd_FTPT_1948-1997 before 1997 and Table 604 of the NIPA Accounts afterwards. Data before 1997 uses a slightly different industry categorization than the more recent BEA accounts (based on NAICS 1997 and 2007, respectively). We verify that there are no jumps. Employment data are available for the 20 sectors back to 1948 and the 62 industries back to 1977 . We report results using both, but use sector-level productivity as our baseline to cover a longer history.

\section{A.2.2 Foreign Sales Adjustment}

We use the BEA's Data on the activities of U.S. multinational enterprises to estimate the share of foreign sales at the industry-level. We gather foreign affiliate sales (sales by 'majority-owned nonbank foreign affiliates of nonbank U.S. parents') from Table III.E8 and U.S. parent sales ('sales of nonbank U.S. parents of nonbank foreign affiliates' from Table II.K.1. ${ }^{6}$ Data are reported under a consistent definitions from 1983 - 1998. After 2009, BEA accounts were redefined to include both bank and non-bank parents. We select the tables that most closely match prior definitions (Table II.D.11 for affiliate data and Table I.K.1 after 2009 for parent data). We verify that there are no major jumps that may bias the results. ${ }^{7}$

\footnotetext{
${ }^{5}$ It is important to keep this segment because several stars map to it (e.g., GE). We assume labor productivity, prices and export adjustments are equal to the weighted average of the remaining industries.

${ }^{6}$ Table III.E.8 is named Table 33 from 1983-1988, Table 37 from 1990-1993. Table II.K.1 is named Table 54 in 1989, Table II.L.1 from 1999-2003, and Table II.M.1 from 2004-2008.

${ }^{7}$ There is a jump for Finance, as expected, so we use post-2009 data for banks throughout.
} 
We define the share of foreign sales as the ratio of foreign affiliate sales to the sum of foreign affiliate sales and U.S. parent sales. We use Majority-owned affiliates because they correspond to the activities over which U.S. parents exert unambiguous control; and which are consolidated in parent financial accounts. ${ }^{8}$

Industry categorizations are based on SIC segments before 1998 and NAICS segments afterwards, and nearly match those of GDP by industry accounts. We select the level of aggregation that most closely matches Gross Output accounts, using SIC codes before 1998 and NAICS codes afterwards.

Foreign sales were relatively stable in the 1980s, so we hold the share of foreign sales flat at the 1983level for all prior years. ${ }^{9}$ We also fill the share of foreign sales forward after 2015 . Firms that cannot be mapped to a particular MNE industry are assigned the value for all private industries.

\section{A.2.3 Census Concentration}

Last, we obtain sales, employment and payroll data for non-manufacturing industries from the US Economic Census' Concentration accounts. See link for additional details. Data includes breakdowns for the top 4, 8, 20 and 50 firms in each industry along with industry totals. They are based on SIC segments from 1987 to 1992 and NAICS segments afterwards. Data for service industries are reported by tax-paying segments. We keep tax-payable firms because they are reported consistently over time and are closest to our analysis. Data for wholesale trade are reported as a total and by type of merchant (e.g., merchant wholesaler, manufacturer). We keep only the total.

We select the reported NAICS and SIC industries that most closely match those in GDP by Industry accounts (NAICS and SIC-based, respectively). We then compute wages for each industry and the top-4 firms in each industry as the ratio of 'Annual Payroll' to 'Paid employees for pay period including March $12{ }^{10}$ We define the wage-adjustment as the ratio of wages at the top-4 firms in each industry to average industry wages. We only apply the adjustment after 1997 because data before cover only subset of nonmanufacturing industries. Industries for which are are not available are assigned the weighted average across industries).

We also implement a labor productivity decomposition treating the top-4 firms in each industry as a 'single firm'. We use the BEA price indices described above to deflate sales at the industry-level.

\section{A.3 Firm-level data}

Our firm-level data source is the Compustat-CRSP merged database. Specifically, we download the following tables:

- Compustat funda, which contains firm-level financials

- Compustat company, which contains company characteristics such as NAICS codes and headquarter location

\footnotetext{
${ }^{8}$ According to page 47 of Raymond J. Mataloni (1995), "data for U.S. parents and MOFA's can * be summed to measure the global production and employment of MNC's over which * U.S. parents exert unambiguous control. Changes in the U.S.-parent share of * these measures indicate changes in the domestic (U.S.) share of worldwide U.S.- * MNC production."

${ }^{9}$ Banks are assigned the 2009 level for all prior years because they were not covered by the MNE accounts before.

${ }^{10}$ We could use Q1 payroll, but it overstates the differences because most bonus payments are included in Q1.
} 
- CRSP msf, which contains the number and price of shares by month

- CRSP ccmxpf_linktable, which contains a mapping table between CRSP and Compustat

We apply standard screens to the Compustat file (consol = "C", indfmt = "INDL", datafmt="STD", popsrc="D" and curcd = "USD"), and include only US-located firms (LOC = USA). We exclude firms with weakly negative or missing assets, sales or employment (AT, SALE, EMP) as well as missing OIADP.

We map firms to BEA industries using NAICS 2007 codes, which are used as the basis of BEA accounts. In some cases, Compustat reports varying NAICS hierarchies over time. We map retired codes to the NAICS 2007 hierarchies using the Census Bureau's concordances. Missing NAICS codes are filled in using the most common NAICS code among the firms with the same SIC code. Firms with SIC or NAICS codes of 99* are mapped to an 'Other' category as described above.

The market value of equity for each issuance is defined as the product of CRSP variables PRC and SHROUT. ${ }^{11}$ We sum across issuances of a given (mapped) GVKEY to obtain market value of equity at the firm-level. We keep the values as of December of each fiscal year, as defined in Compustat. Missing market values are filled in using Compustat (PRCC_C * CSHO) whenever possible. ${ }^{12}$ Any remaining missing value is set to zero, to avoid excluding those firms from the analysis. Market Value of Assets is defined as the sum of market value of equity and long term debt (Compustat DLTT).

\section{A.4 Details of Construction of Main Figures}

Figure 1. Top panel: we define firm-level employment shares as the ratio of Compustat field EMP to total U.S. civilian employment (FRED series CE16OV). Aggregate by adding across firms that belong to a given star population.

Bottom panel: define firm-level sale-to-GDP ratios as the ratio of Compustat field SALE to US GDP (FRED series GDPA). For domestic sales, multiply by the industry-level share of foreign sales defined above. Aggregate by adding across firms that belong to a given star population.

Figure 2. Deflate Compustat sales using the BEA gross output prices at the industry level. Then define quality-adjusted labor productivity as the ratio of deflated sales to the product of firm-level employment and the employment quality adjustment, defined above. Compute log changes and smooth using a three-year forward-looking moving average. Truncate the smoothed values at -0.3 and 0.5 to reduce the impact of outliers, then aggregate by adding across firms that belong to a given star population using the appropriate Domar weights.

Figure 3 and 4. To compute employment growth, $g_{i, t}^{n}$, begin by computing the annual log-change in firmlevel employment. Then smooth using a three-year equally-weighted forward-looking moving average and

\footnotetext{
${ }^{11} \mathrm{PRC}$ is reported as negative when $\mathrm{XXX}$. We take the absolute value.

${ }^{12}$ This is more common early in the sample. Note that there is a slight discrepancy relative to the CRSP calculation. PRCC_C denotes the price of the main issuance for each GVKEY, at calendar year-end for the corresponding fiscal year. CSHO denotes shares outstanding as of fiscal year-end. Whenever a firm has more than one issue or has a fiscal year-end other than December, the CRSP and Compustat values might differ. That said, differences appear to be small and we prefer to keep the values for as many firms as possible.
} 
truncate the smoothed values at -0.3 and 0.5 to reduce the impact of outliers. Then aggregate by adding labor productivity contributions across firms that belong to a given industry

$$
g_{t}^{r *} \equiv \sum_{i \in S_{t}}\left(z_{i, t}-\bar{z}_{I, t}\right) g_{i, t}^{n} \times \frac{e m p}{G D P}
$$

as described in the text. We truncate labor productivity differences at $-50 \%$ (-25\% for stars) and $450 \%$ to mitigate the impact of outliers.

The different measures in the Figure use different benchmarks to compute $\bar{z}_{I, t}$. Census benchmarks are defined above. The Compustat benchmark is the employment-weighted average labor productivity across firms in a given industry.

Figure 5 and 6. Sum labor productivity contributions of Figure 2 and Figure 4. We use the cost-based Hulten contribution without quality adjustments and the average of Compustat and Labor-quality adjusted BEA measures, but results are robust to other choices. For Census contribution, implement the same decomposition described above but treating the top-4 firms in each industry as a 'star'. Include the SIC and NAICS industries that most closely match the corresponding industries in the BEA's GDP by Industry accounts (e.g., for retail trade, use NAICS 44-45, for transportation industries use NAICS-3 codes and for professional services use NAICS-4 codes).

Figure 6. Total contribution of industry stars defined as above. Aggregate labor productivity growth defined as the $5 \mathrm{Y}$ centered moving-average labor productivity growth of Fernald (2014). Non-star contribution equals the difference between the (smoothed) labor productivity growth and the industry-star contribution.

\section{B Additional Results}

Figure 7 compares the labor productivity of the stars to that of other companies. The Top Panel uses other publicly traded firms (i.e., Compustat) in the same industry as a benchmark: it plots the weighted average $\log$ difference in total sales per employee. It shows that the stars of the 1980s and 1990s had higher sales per employee than other established firms. In the 2000s, however, that difference has vanished. The Bottom Panel uses industry productivity as a benchmark, using industry data on gross output per employee from the BEA. For industry stars, we again observe no trend. For the Top 20 we observe a relative increase, but as we show later, this is entirely explained by increasing differences in labor quality (the top 20 stars higher more productive and expensive labor inputs).

Figure 8 shows that the stars' profit margins have increased and remained high since the late 1990s. Much of the increase, however, is shared by other non-star firms. Still, it is true that margins have increased in recent years somewhat more for the stars.

Figure 9shows the impact of oil price shocks on our measure of productivity growth by reallocation.

Figure 10 shows our wage adjustment series, which is based on non-manufacturing industries at the Top-4 firms vs. the rest. 
Figure 7: Productivity and Profits of the Stars
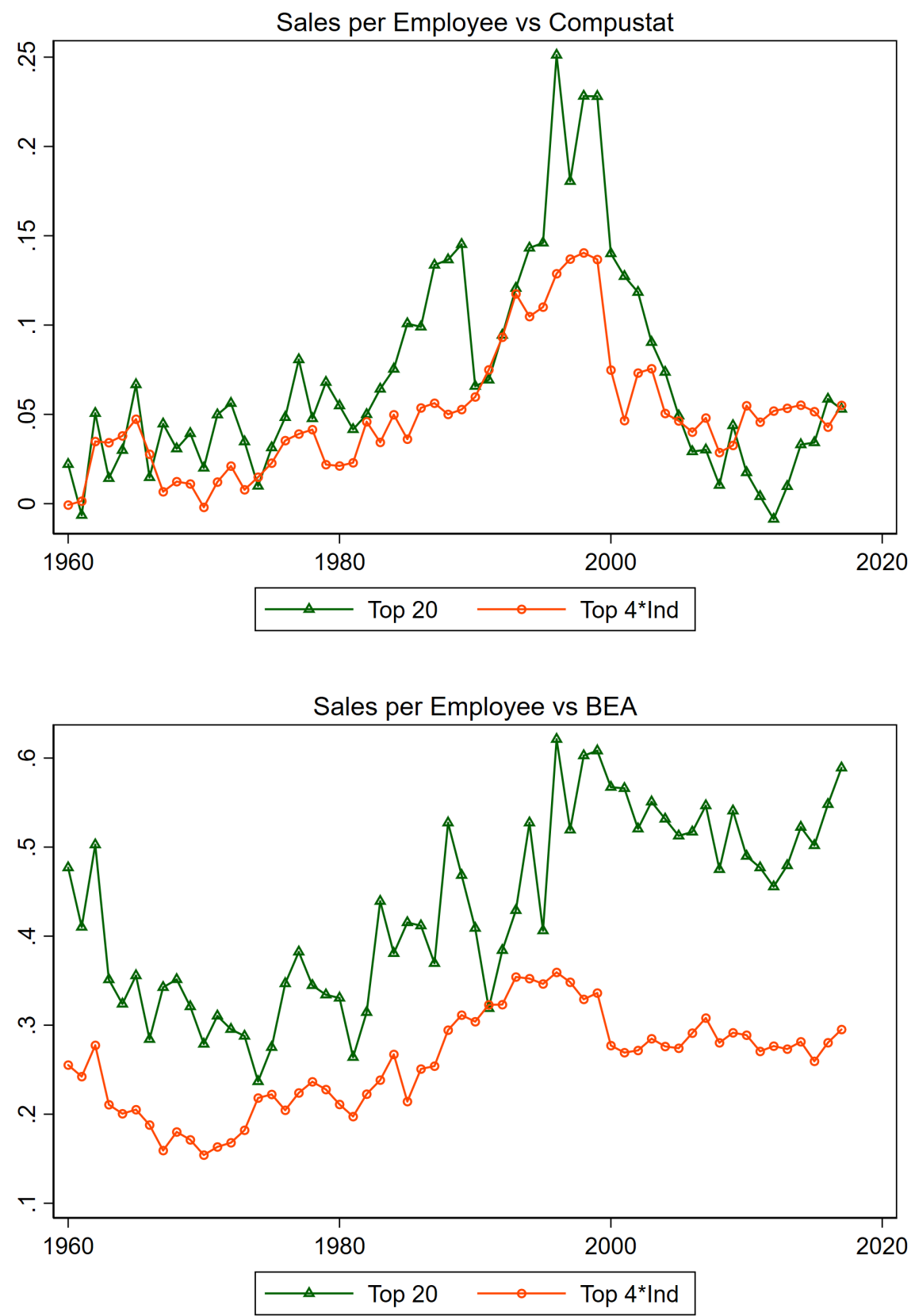

Note: Figure plots weighted average log-difference in sales per employee between star firms and their corresponding Compustat industry and BEA sector, respectively. 
Figure 8: Profits of the Stars

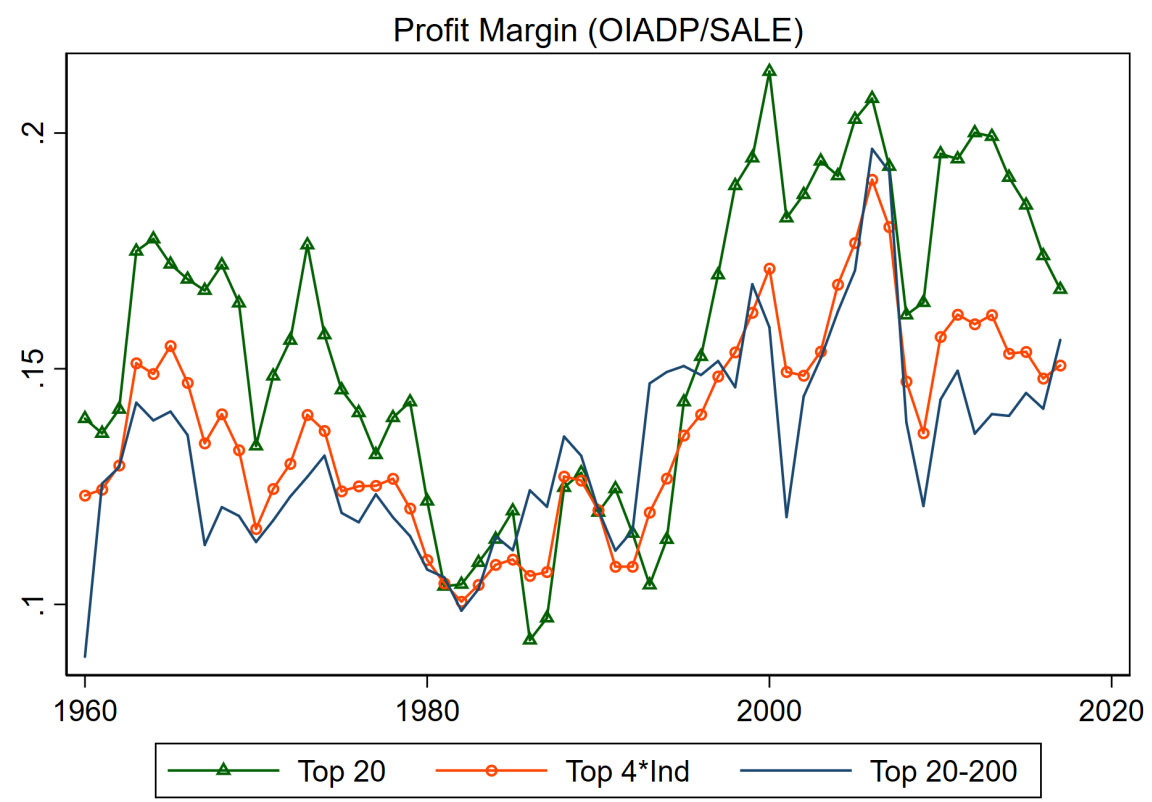

Note: Figure plots weighted average profit margin by population.

Figure 9: Impact of Oil Shocks

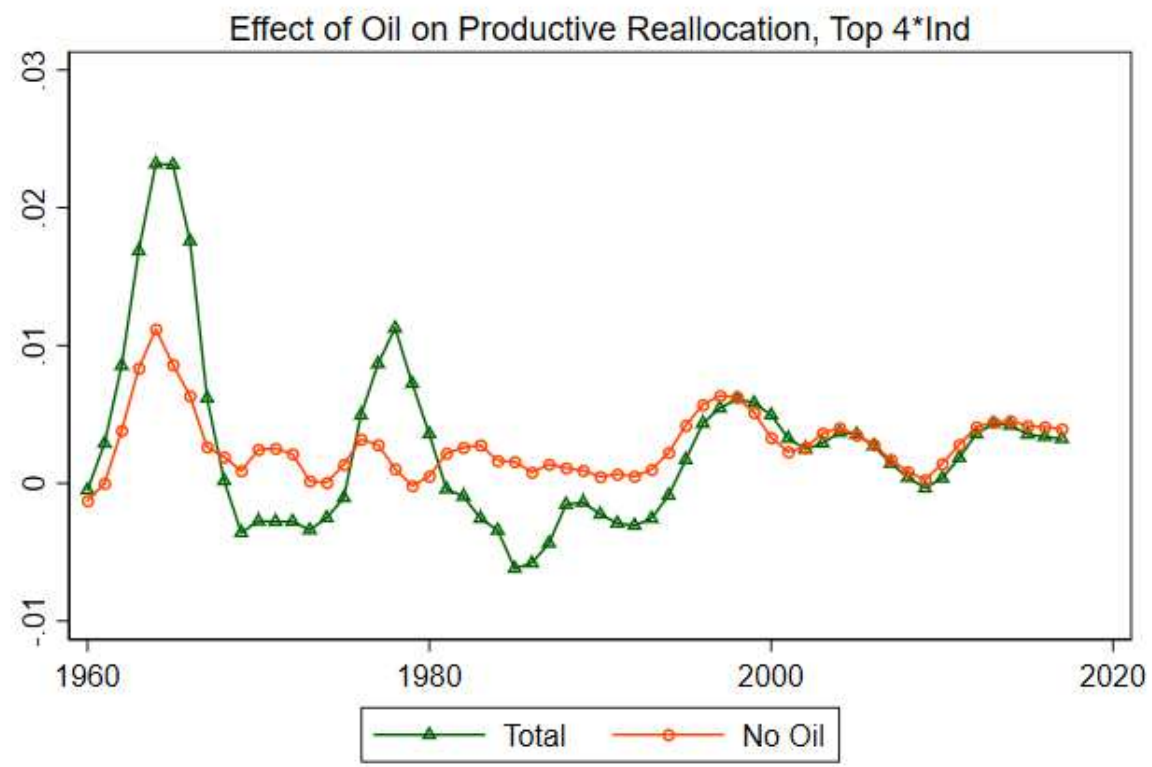

Note: BEA-based with wage adjustment

Note: BEA-based with wage adjustment 
Figure 10: Relative Wages
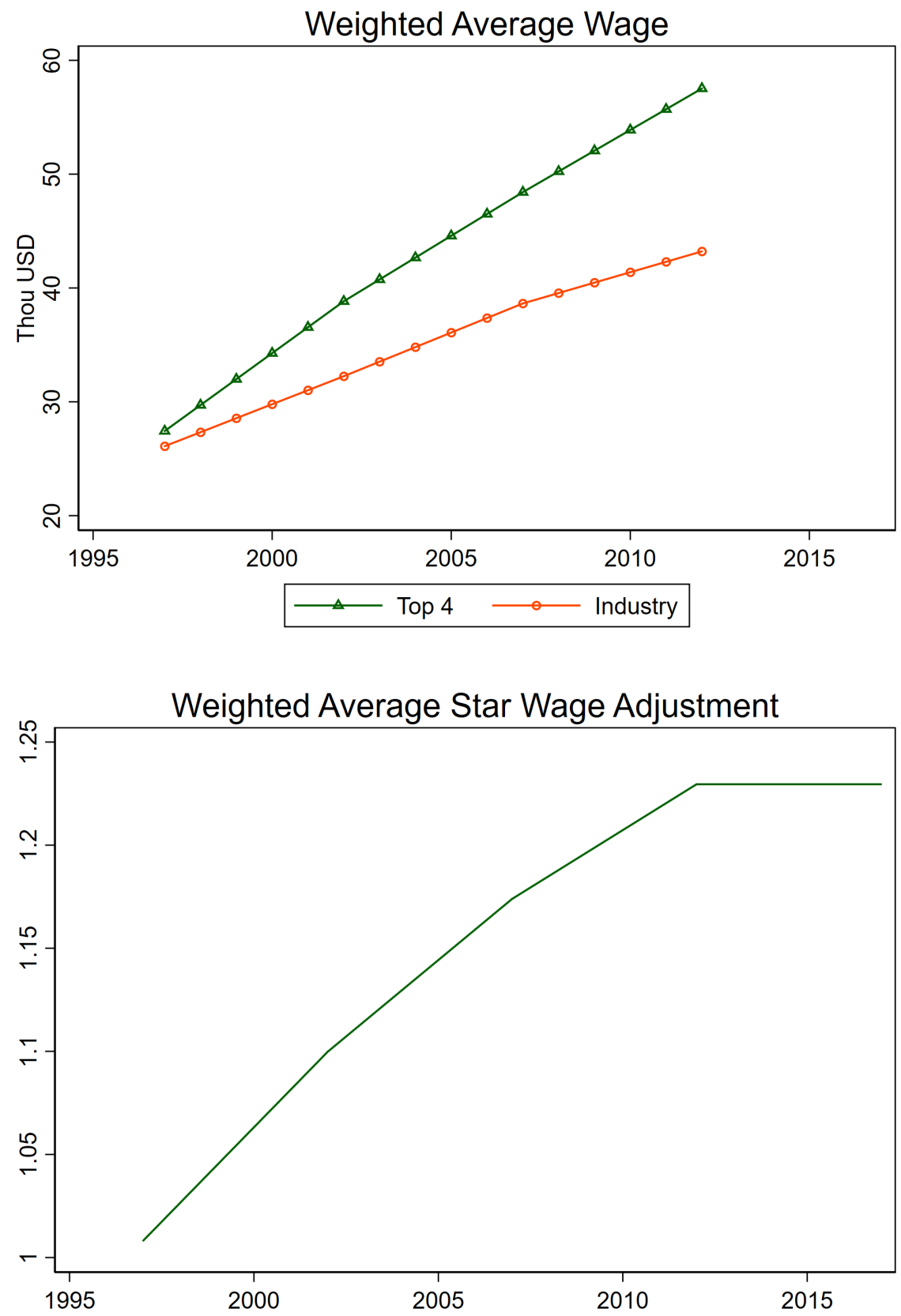

Note: BEA-based with wage adjustment 
Table 1: Overlap Across Star Definitions

\begin{tabular}{lcccccc}
\hline Out of I contained in & ME_top20 & ME_top100 & ME_top4xInd & SALE_top20 & SALE_top100 & SALE_top4xInd \\
\hline 1_ME_top20 & 1 & 1 & .92 & .55 & .93 & .8 \\
2_ME_top100 & .2 & 1 & .61 & .17 & .59 & .5 \\
3_ME_top4xInd & .09 & .29 & 1 & .07 & .24 & .68 \\
4_SALE_top20 & .55 & .84 & .73 & 1 & 1 & .91 \\
5_SALE_top100 & .19 & .59 & .51 & .2 & 1 & .6 \\
6_SALE_top4xInd & .08 & .24 & .68 & .09 & .29 & 1 \\
\hline
\end{tabular}

Figure 11 shows two measures of Outsourcing. The top plot shows the foreign affiliate share of employment for U.S. Multinational Enterprises. The bottom shows the share of all US workers who are working for business service firms - a measure of Domestic outsourcing suggested by Dorn et al. (2018). Outsourcing increased according to both measures, but the trends are fairly smooth. There does not appear to be a major break in 2000.

\section{Alternate Star Definitions}

The main body reports results ranking firms by market value of equity. Two alternate definitions could be used: market value of assets and sales. We selected market value of equity because it most closely resembles the discussion of superstar firms. By 2016, the Top 20 by market value of equity includes the complete GAFAM. The complete GAFAM also appears when using MVA, but Finance firms receive a substantial boost due to leverage. Fannie Mae and Freddie Mac top the ranking, which are hard to classify as superstars of the last decade. Sales over-weights manufacturing firms and discounts tech firms which are at the core of the discussion. In fact, only Apple and Amazon appear in the Top 20 by sales.

Table 1 measures the overlap across star definitions more formally. For instance, the second row first column shows that $20 \%$ of the Top 100 stars by MVE belong to the Top 20 stars by MVE, as expected. For the reasons discussed above, we find a relatively low level of overlap across definitions.

The above might be concerning if conclusions vary widely across definitions. However, as shown in the following figures, all conclusions remain when using sales instead of market value to rank firms. Figure 19 also provides more details of the comparison between Compustat and the Census. 
Figure 11: Outsourcing and Offshoring

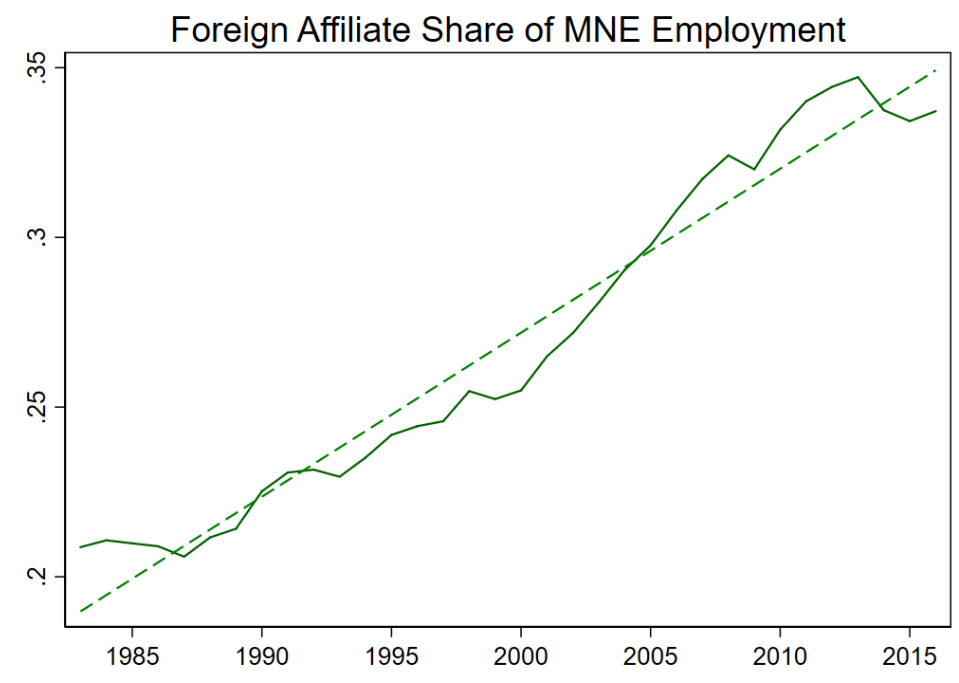

Figure 1: The Fraction of Workers working in Business Services

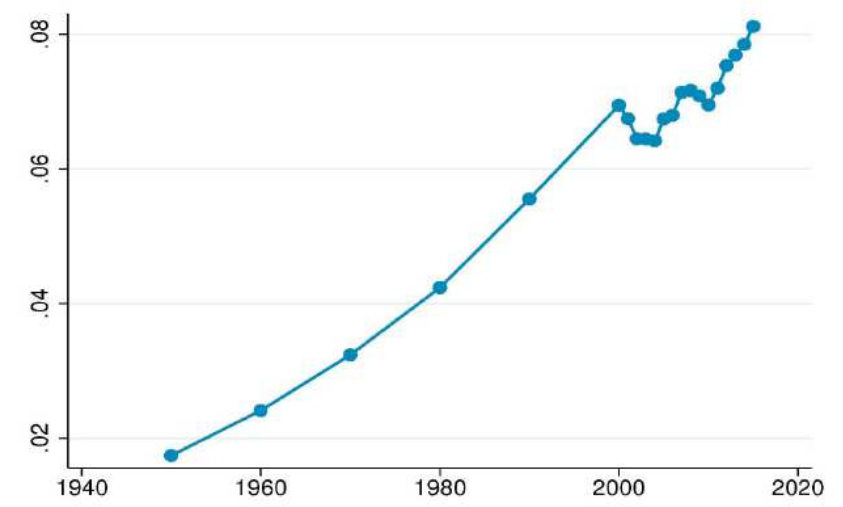

Note: The figure shows the fraction of all workers in the US working for business service firms. The fraction is calculated using IPUMS Decennial Census data from 1950 to 2000 and the Amercian Community Survey data from from 2000 to 2015. Business service

firms are defined as firms with 1950 IPUMS industry codes for trucking (ind1950=526), warehouse (ind1950 $=527$ ) industries or miscellaneous business services (ind1950=808).

Note: Top plot from BEA MNE accounts. Bottom plot from Dorn et al. (2018) 
Figure 12: Comparison of Firm Rankings by Measure

\section{Top Firm Rankings by Measure}

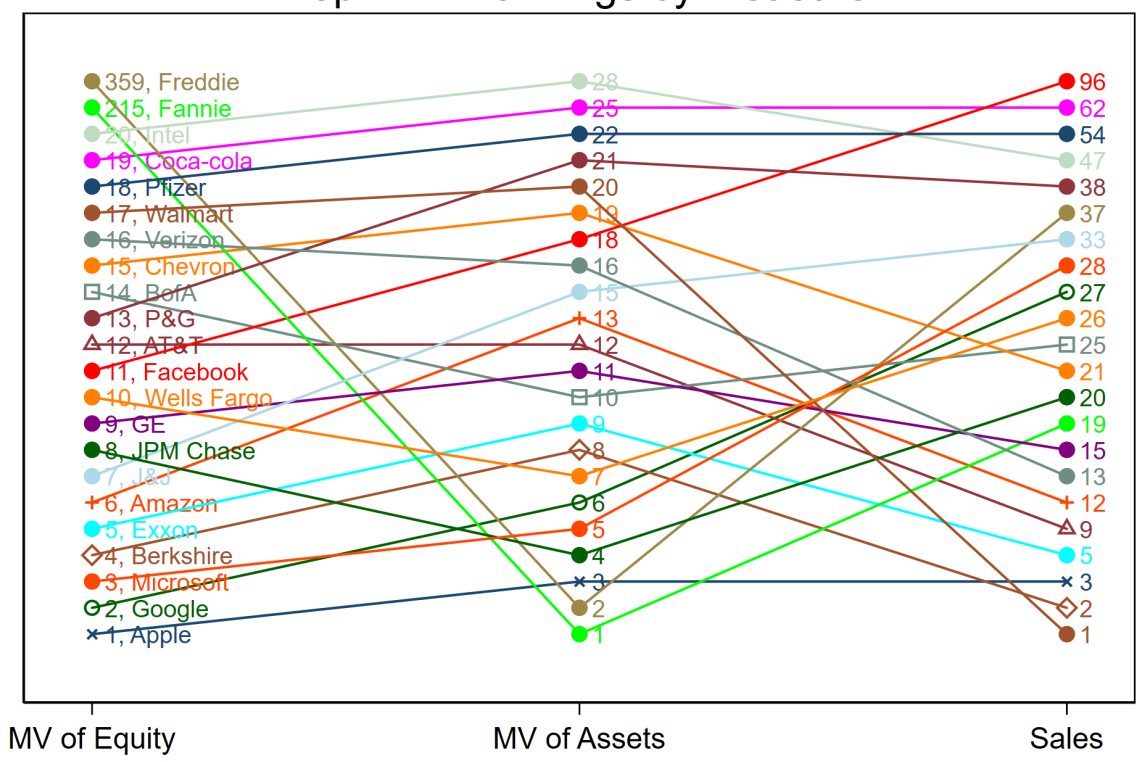

Note: the figure plots the ranking of the Top 20 firms by market value of equity in 2016, according to three measures: market value of equity, market value of assets and sales. 
Figure 13: Footprint of the Stars
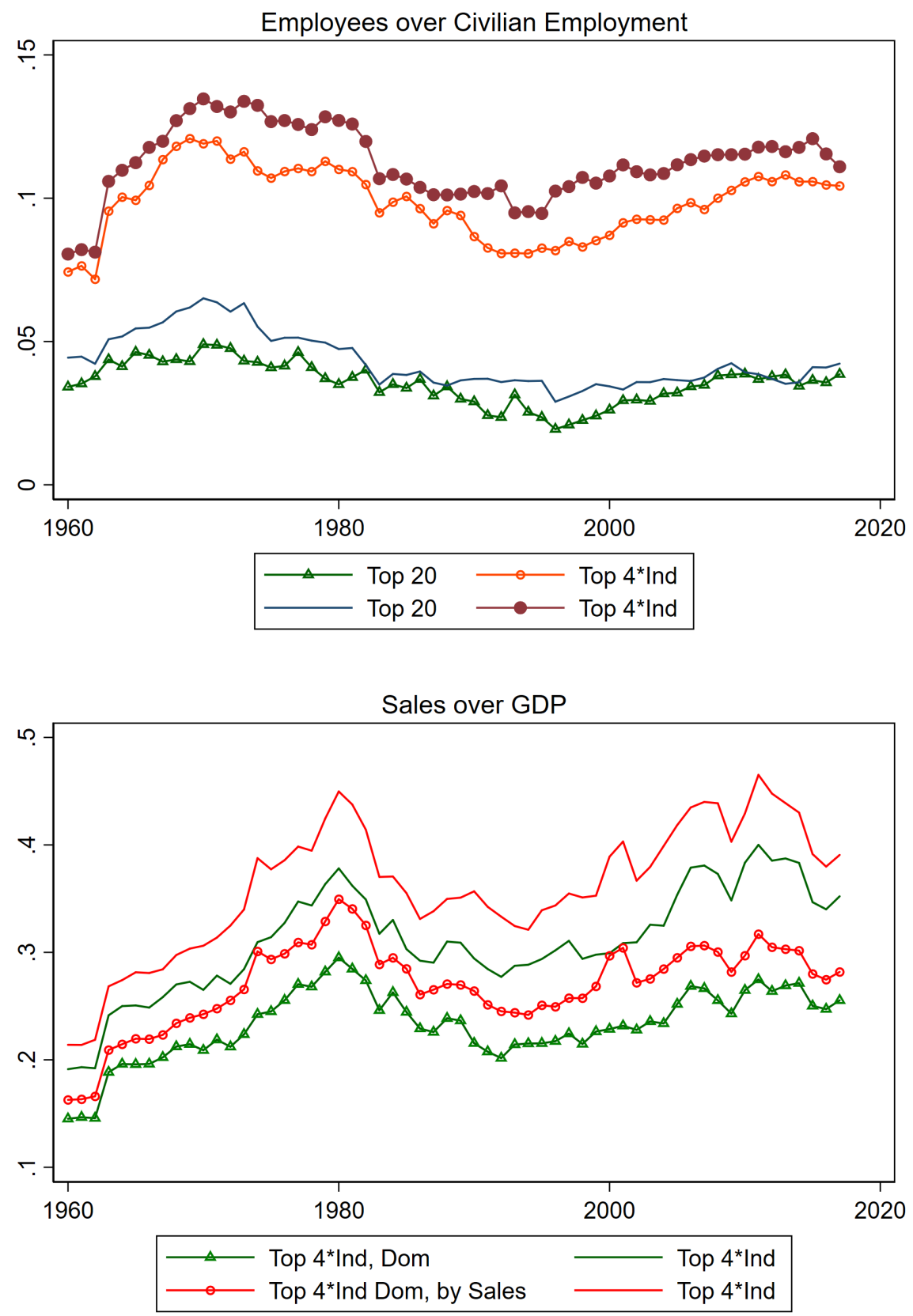

Note: See text for definitions. For bottom panel, "Dom" means domestic sales, while "Top 20" means consolidated (global) sales of Top 20 firms by market value. Stars defined based on sales. 
Figure 14: Hulten Contributions of the Stars
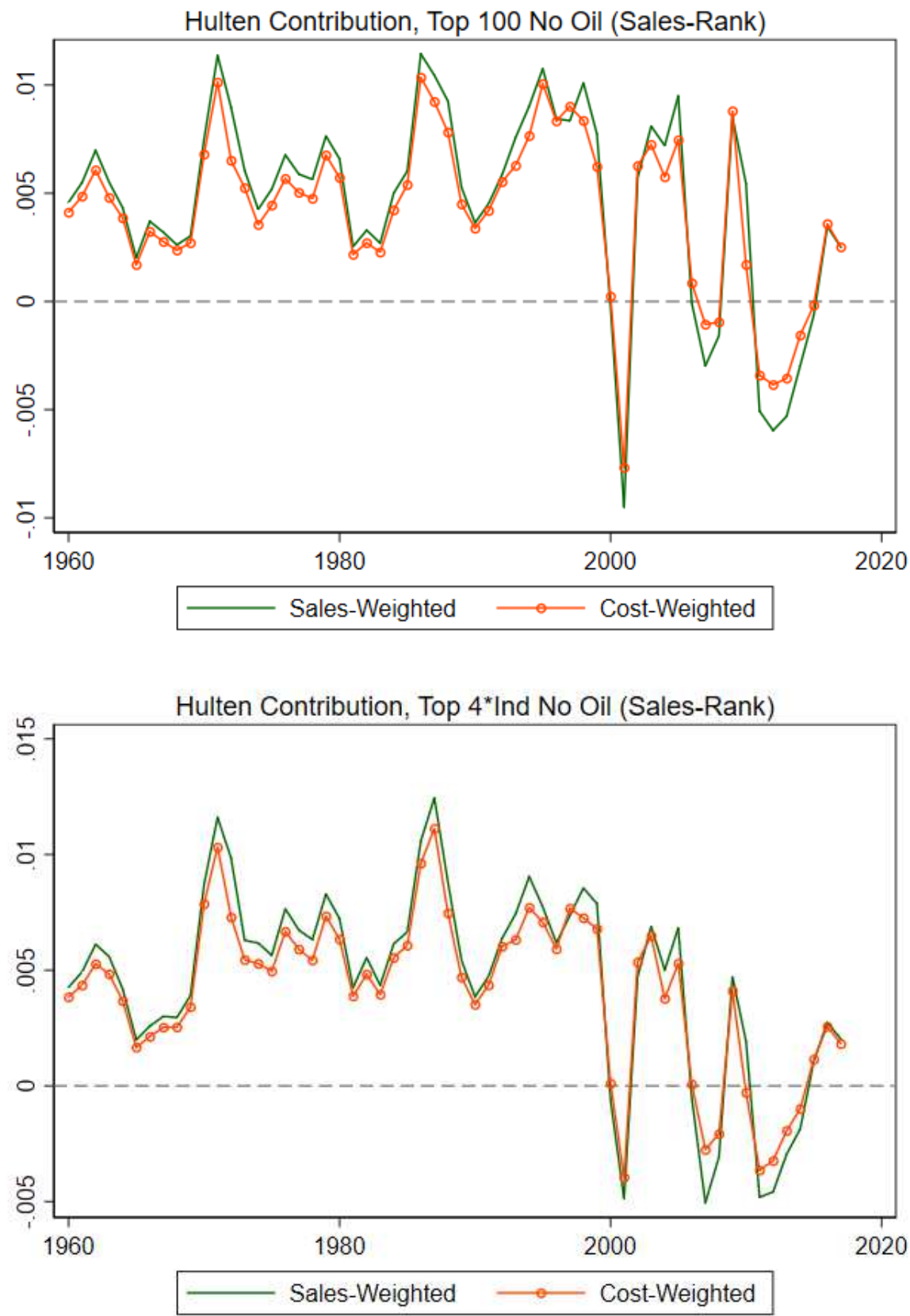

Note: Green line uses sales/GDP as Domar weight. Red line uses cost/GDP as Domar weight. Stars defined based on sales. 
Figure 15: Different Benchmarks for Measuring Reallocation

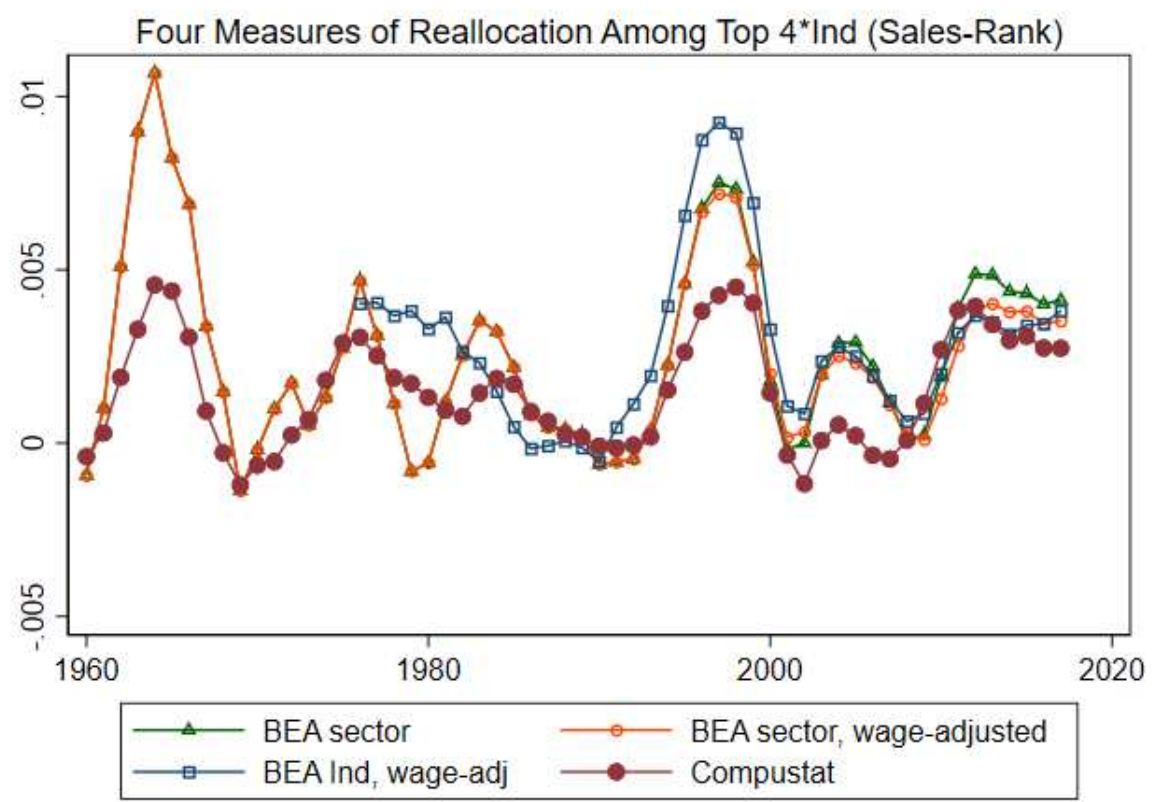

Note: 4 measures of reallocation productivity, using 4 benchmarks: average sector productivity from BEA; sector BEA adjusted for labor quality; industry BEA and Compustat industry average. BEA industry productivity available only after 1977. Stars defined based on sales.

Figure 16: Reallocation Contribution of the Stars

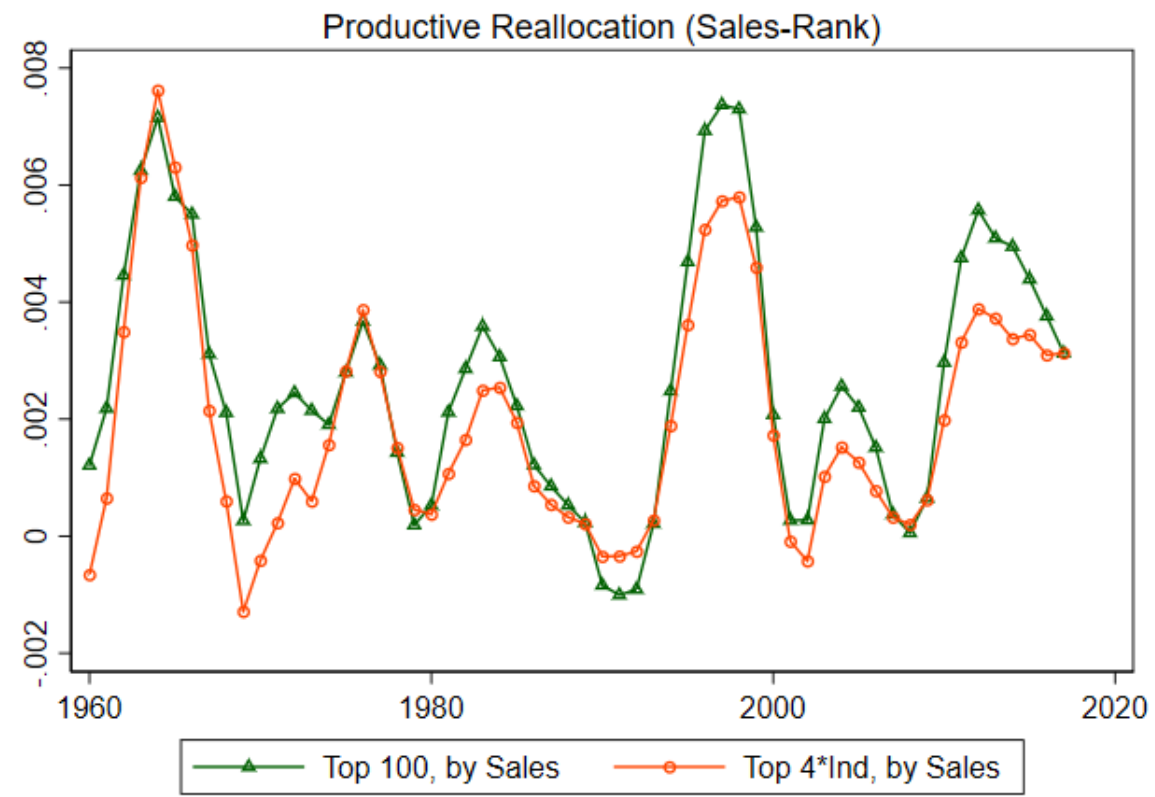

Note: Reallocation productivity defined as average of Compustat and Labor Quality Adjusted measures. Stars defined based on sales. 
Figure 17: Total Contributions of the Stars, by Sales

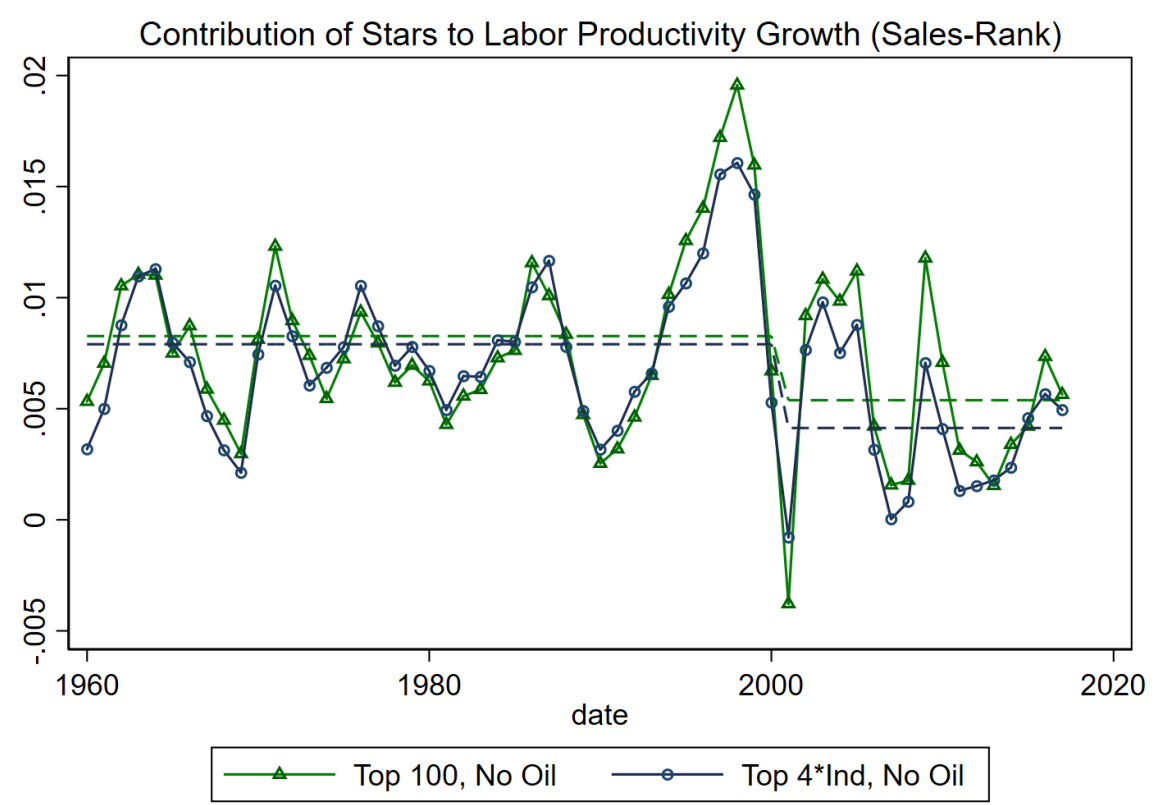

Note: the figure plots the contributions of sale-based star firms to US labor productivity growth. The dashed lines show the averages for 1960-2000, and 2001-2016. Top 100 averages: 83 bps down to 55 bps. Top 4 by Industry averages: 79 bps down to 41 bps.

Figure 18: Total Contributions of the Stars vs. U.S. Labor Productivity growth

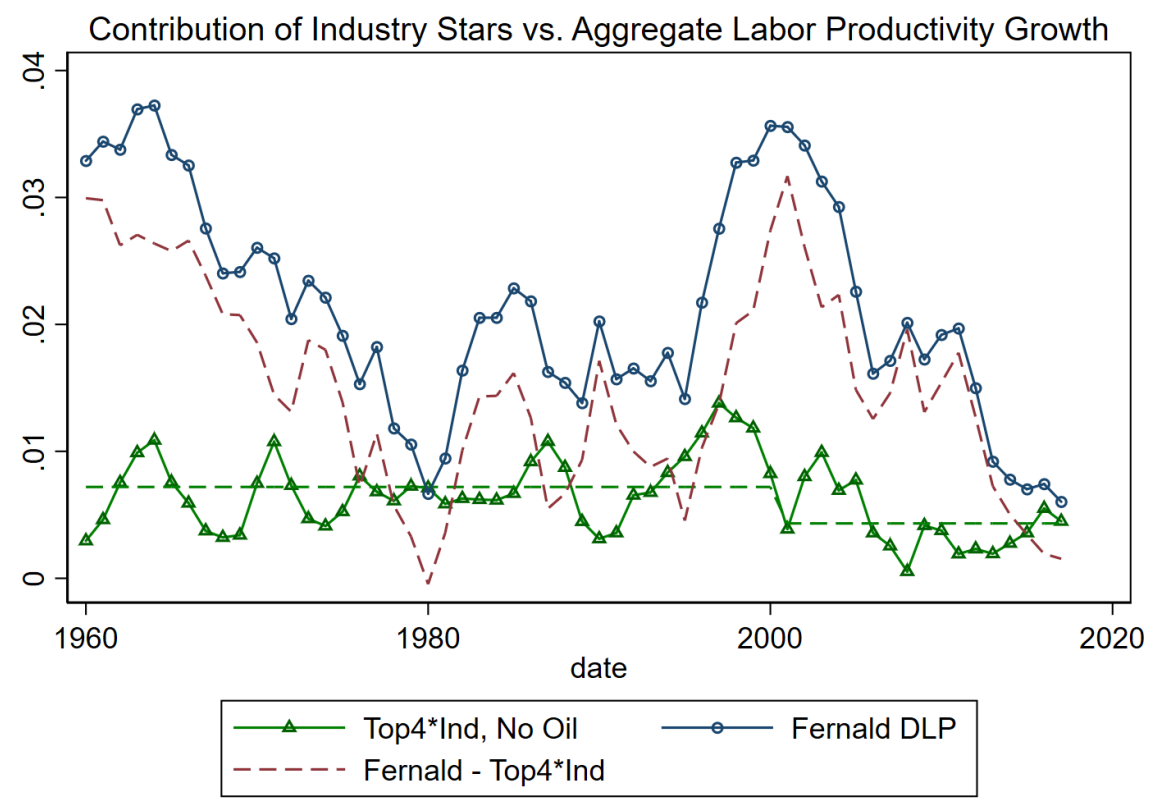

Note: the figure plots the contributions of star firms to US labor productivity growth, including 5Y MA growth in U.S. labor productivity as measured by Fernald (2014). 
Figure 19: Comparison of Total Contributions of the Stars: Compustat vs. Census

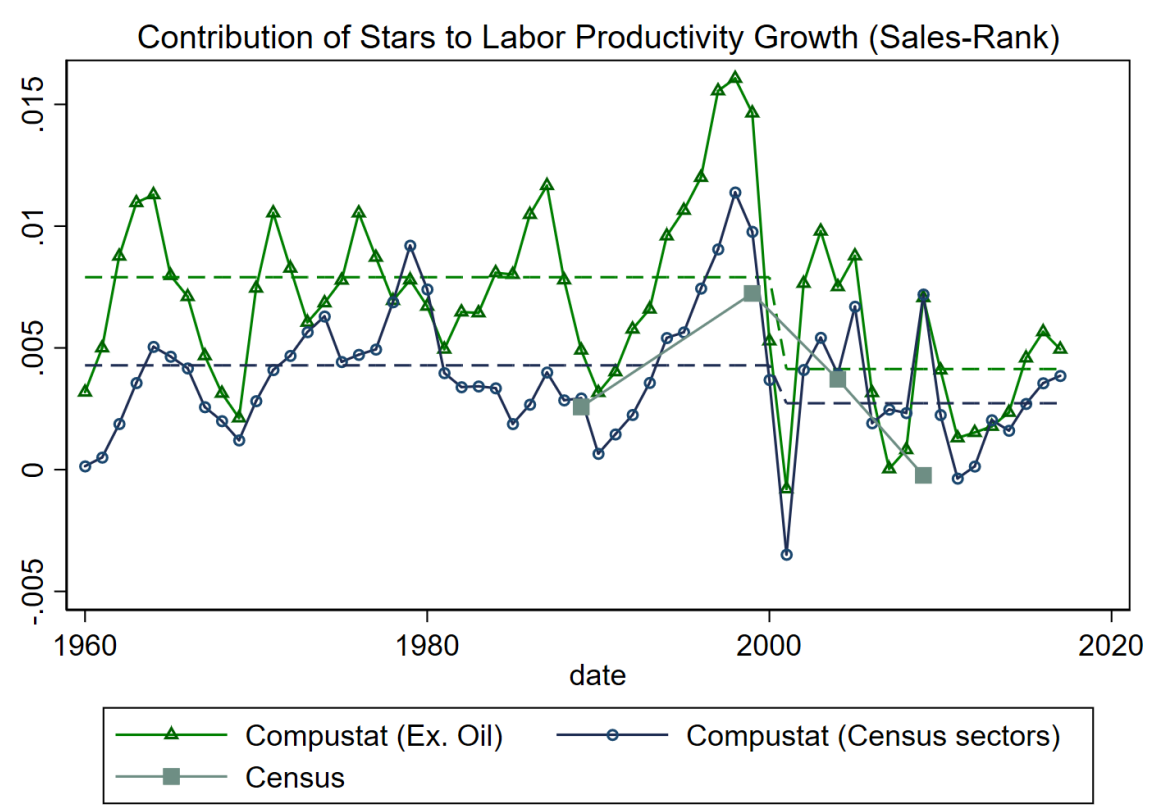

Note: the figure plots the contributions of top $4 *$ ind sale-based stars to US labor productivity growth. Green line with triangles based on Compustat, including all industries except oil. Blue line with circles based on Compustat, including those sectors for which Census concentration data includes employment (Non-manufacturing excluding Agriculture, Mining and Construction). Gray line with squares based on the Census concentration data. Each dot represents the change in labor productivity from 19871992, 1997-2002, 2002-2007 and 2007-2012. 